\title{
THE COLUMBIAN GROUND SQUIRREL
}

\section{ITS BIOLOGY AND CONTROAtar Doccumerrs Collectron}

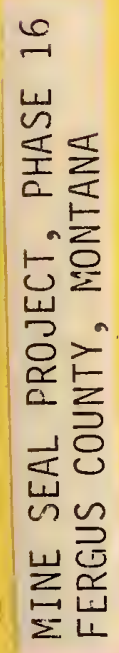

DEC 11988

MONTANA STATE LIBRARY 1515 E. Gth AVE.

HELENA, MONTANA 59620

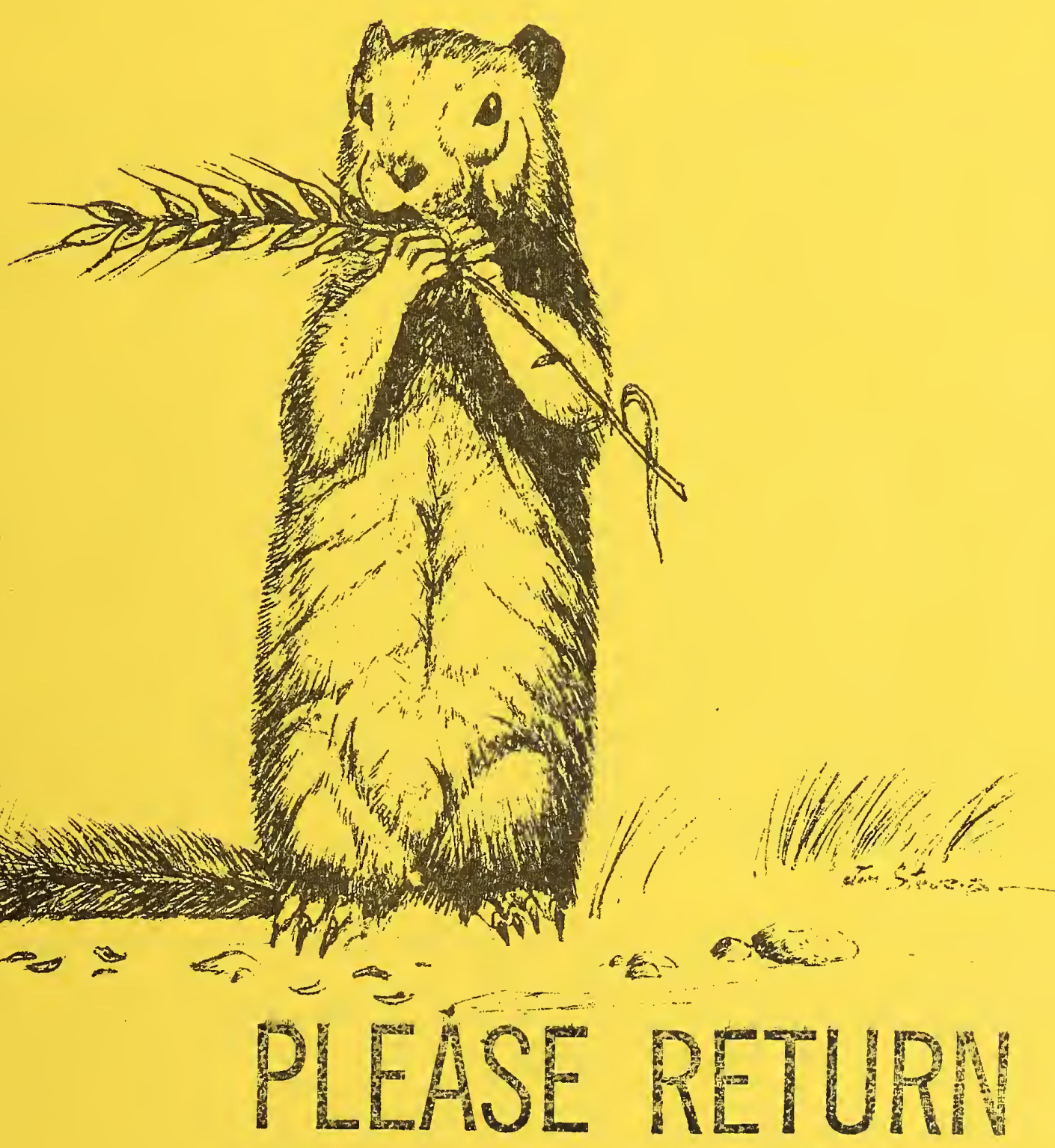

MONTANA DEPARTMENT OF AGRICULTURE

HELENA, MONTANA $5962 ?$ 
MAR 262004

Digitized by the Internet Archive in 2016 
I'HE COIUNIBIAN GROUND SQUIRREL

ITS BIOLOGY AND CONTROI.

\section{BIOLOGY}

The Columbian ground squirrel. (spermophilus columbianus) is a large ground squirrel found in Montana from the east slope of the Continerital Divide westward. They are found from above tree line in the mountains to the lowest valleys. Columbians are usually absent from dense forest areas but are commonly found in open forest and forest edges. Ground squirrels are excluded from areas where the water table is high enough to keep the soil wet. Banks, hillsides and sloping ground seen to be preferred habitat.

The Columbian grourd squirrel is easily distinguished from other Montana ground squirrels by its larger size and distinctive coloration. An average adult weighs more than a pound. Its head and body measure 10 to 12 inches in length. The tail is 3 to 5 inches long and tends to be bushy, particularly when the squirrels are excited. Reddish-brown fur is found on the nose, forelegs and hindquarters. The back and upper Iimbs are mottled gray and brown.

Columbian ground squirrels hibernate for six to seven months each year. Their active period varies with local weather conditions and elevation. In most areas they are active between March and August. Hibernation in late summer is a response to drying vegetation and high temperatures. The majority of local population enters hibernation within a one to two week period. Small numbers of squirrels, usually young-of-the-year, may be seen several weeks after most of the population has begun hibernation. Squirrels hibernate in grass lined pockets below the frost line. They neither eat or drink, living on body fat accumulated during the previous summer. Body temperature drops to about $38^{\circ}-42^{\circ} \mathrm{F}$ during hibernation. Bodily functions are greatly reduced allowing the squirrels to slowly use their accumulated fat. Squirrels arouse periodically to eliminate small quantities of accumulated body wastes.

Squirreis emerge from hibernation in most areas in late March and early April. Time of emergence from hibernation is affected by snow cover, soil temperature, weather conditions and elevation. Emergence may vary within a small area because of differences in slope and snow cover. Squirrels colonies located on south-facing slopes or flat areas may emerge 1 to 3 weeks before a colony located on a north-facing slope in the same area.

The males emerge from hibernation first, one to three weeks before the females. Breeding begins shortly after the females emerge and continues about two weeks. One male may breed with more than one female. After the breeding period the female prepares the natal nest and spends much of her time during late gestation and early litter rearing in the burrow and is relatively irlactive above ground. Columbian ground scuirrels have a gestation period of 
about 24 days and have one litter per year of four to five young. The young, born helpless and dependent on their mother for care, emerge from the burrow at about 4 weeks of age. They begin foraging on vegetation soon after emergence. They are weaned and independent from their mother at or shortly aiter emergence from the burrow. By late summer juveniles are $60 \%$ of the average adult weight (see Figure 1).

Ground squirrels eat à wide variety of vegetation. They seem to feed on most available plant species but prefer different plants at different seasons generally selecting the most succulent species. As vegetation matures, squirrels include seeds in their diet as they become available. The high caloric and oil content of seeds is important for the accumulation of body fat needed to carry the squirrels through hibernation. Green vegetation continues to be an important dietary component because, in most cases, it is the squirrels' only source of water. The general arying of the environment in mid-to-late sumner is probably one of the factors causing squirrels to enter hibernation. Squirrels will supplement their diet by feeding opportunistically on insects ana carrion.

Columbian ground squirrels are often described as selective and fastidious feeders. Seeds are hulled and eaten individually much of the time. Columbians tend not to pouch food in their cheek pouches and little food is stored in the burrow system.

Ground squirrels seem to have difficulty maintaining their body temperature during cold or hot periods. Squirrels exposed to hot temperatures for more than a few hours are likely to die. During cold, inclement days they remain in their burrows much of the time. When days are hot most squirrel activity occurs in the mornings and late afternoons.

Predators include badgers, weasels, coyotes and foxes, and birds of prey. Naive juveniles are likely the most vulnerable targets for hawks and canids. Badgers are probably the most consistent and successful predator on Columbian ground squirrels.

\section{DAMAGE}

In their native and undisturbed habitats, rodents are largely beneficial. Burrowing and digging activities increase habitat diversity resulting in complex interdependent plant and animal. communities. Digging activities aid in soil building, soil. aeration and moisture retention. Rodents are the major prey item for many avian and mammalian predators.

When the Columbian ground squirrei occurs in lands used for agricultural production, crops are often damaged. Ground squirrels damage grain crops by consuming and trampling the grain plants. Damage most often occurs when squirrels reside in uncultivated border areas and enter the crop edges to feed on the grain plants. Forage crops, such as alfalfa, pasturelands and rangelands are ofter Inhabited by ground squirrels. Squirrel feeding and mourds 
covering the crop reduces production and available livestock forage. Squirrel mounds can cause costly equipment damage to machinery used to harvest forage crops. Mounds and burrow openings present a potential hazard to livestock. Rurrowing activity may contribute to increased soil erosion and provide sites for undesirable weedy plants to grow.

CONTROI, METHODS

Where high populations of ground squirrels exist and pose a serious pest problem, it is sometimes desirable to manage local populations to reduce economic damage.

A. CULTURAI AND BIOLOGJCAL

Cultural and biological controls, while not being a total answer to reduce grourd squirrel damage, are part of an integrated control approach. Frequent crop rotation or tillage of the soil often helps discourage dense populations of rodents within an area. Border areas can still be populated with ground squirrels and severe damage to crops can occur along field eages. Frequent flood irrigation can reduce rodent problems in some cases.

Coyotes, fox, weasels, owls, hawks, eagles, badgers, skunks, and snakes, and other predators prey upon ground squirrels and other rodents. While their impact on rodent populations may not eliminate rodent damage, predators contribute to the overall control effort and their presence should be encouraged.

\section{B. SHOOTING}

Shooting may provide scme relief from ground squirrel damage in small acreage situations or as a follow-up or maintenance control method after other control practices. It is an expensive and time-consuming practice. This practice may be dangerous if conducted rear occupied dwellings or livestock.

\section{TRAPPING}

Traps are best suited for removal of small, local populations of ground squirrels where other control methods are unsatisfactory or undesirable. Such areas would include public parks, schools, cemeteries and private yarảs. Trapping is an effective, general safe control method and no license is required.

Leg hold traps or body traps such as the conibear are commonly used. These traps are set directly in front of or over a burrow entrance and must be securely anchored to the ground. No bait is needed. Although generaily safe, certain nontarget animals can be injured or killed, particularly domestic dogs and cats and certain wildlife species such as weasels, badgers and skunks.

Live traps may be set in any areas frequented by ground squirrels. Squirrels are easily caught using grains such as whole or rolled 
cats, peanut butter, fresh fruit, vegetables or greens. Experiment to find the best bait or combination of baits for your area and time of year. Wiring the door of the trap open for several days whlle replenishing the bait daily helps overcome the squirrel's trap shyness and increases trapping success. It is important that traps be securely anchored to the ground.

Dogs cari be a severe nuisance when trapping squirrels. They can damage the traps, carry them off entirely and unnecessarily maul a squirrel captured in a livetrap. If dogs are a problem, the trapping area should be carefully monitored. Squirrels may die of heat stress when caught in livetraps exposed to the sun. For this reason traps should be shaded and the captured squirrels relocated or humanely killed.

\section{BURROW FUMIGANTS}

Burrow Fumigants are products that release toxic gases when used in a burrow system. Irabor and cost of materials usually restrict the use of fumigants to small acreages or sparce populations. They are recommended as a cleanup method after the use of poison bait or in areas where it is considered unsafe to use poison baits. The ignitable gas cartridge is the most commonly available burrow fumigant. When ignited they produce toxic gases, primarily carbon monoxide, and consume available oxygen in the burrow system. Alter the fuse is lit the cartridge is placed well down into the burrow. The burrow opening should then be sealed with soil and tamped tightly with a shovel. Any äjacent burrow opening from which smoke is escaping should be plugged with soil. Cauticn should be exercised when using gas cartridges in dry situations since they are a fire hazard. Gas cartridges are a general use pesticide.

Aluminum phosphide tablets are another type of burrow fumigant that release toxic phospherie gas in the presence of moisture. The tablets should be placed well down into the burrow. A length of 1-2 inch diameter plastic pipe can be used to place the tablet down into the burrow. After removing the pipe, plug the burrow opening with crumpled newspaper or sod, cover with soil and tamp tightiy with a shovel. Treat every burrow opening. Atmospheric humidity and perspiration on the hands cause gas release. Since phosphene gas will absorb through the skin always wear gloves and stand up wind during application. Open the canisters only outdoors and store in a dry area not inhabited by humans, pets, or livestock. Follow label instructions carefully. This is a restricted use pesticide requiring a license to purchase and apply.

Burrow fumigants work most effectively when soil moisture is high enough to contain the gasses within the burrow. Effectiveness will decrease when fumigants are used in dry, sandy or gravelly soils. rime application in the spring or after soil soaking rains or irrigation. 
In recent years anticoagulants have been used to control field rodents. Anticoagulants are agents that inhibit the ability of the blood to clot. Animals receiving a lethal dose die from internal. hemorrhaging and exterral cuts that continue to bleed. Two anticoagulants with the active ingredient, diphacinone or chlorophacinone, are presently registered for ground squirrels in Montana. To be effective the bait must be placed in bait stations and fed on by the squirrels over a several day period.

A bait station is a covered container which holds the bait and aljows access by the squirrels while restricting access to most other animals. Bait stations must be maintained regularly to replenish the bait. They must be placed in sufficient density so all squirrels have an opportunity to feed on the bait and must be maintained for at least 30 days. For these reasons this control method is not generally practical or economical for squirrel populations on large acreages. Like the burrow fumigants and trapping, it is a very useful and effective method for small acreages and public use areas.

\section{F. GRAIN BAITS}

Presently, direct population reduction with toxic grain bait is the most practical method of ground squirrel control on larger acreaces. The Columbian Grourd Squirrel is one of the most difficult species to control with toxic grain bait. Its apparent preference for green foods and suspiciousness of unnatural food sources often leads to poor acceptance of grain baits. For these reasons there are several things that should be done to optimize chances of success in control operations:

\section{BE SURE THAT THE ENTIRE POPULATION IS ACTIVE}

If a portion of the population is in hibernation it does little good to apply baits. Baiting should never be done at the first sign of activity in the spring or when the squirrels start to hibernate late in the summer. Baiting is not recommended late in the gestation period and shortly after the young are born when females are relatively inactire above ground. This period varies locally but it generally begins four to eight weeks after emergence from hibernation. The activity of females can be checked by shooting a number of squirrels (10-20) and checking the ratio of males to females. If the sample is 50 percent or greater in favor of females baiting is appropriate if other factors are satisfied. If the sampled females were nursing young or were in late pregnancy baiting should be postponed until the young are active above ground. At first emergence from the natal burrow young are easily distinguished from adults by difference in size. Once the young are seen foraging away from the burrow entrances baiting can be conducted providing the bait is accepted. 
Columbian ground souirrel feeding habits vary with the time of year. It is important to test the acceptance of untreated grain prior to the use of toxic grain bait. Do this by scattering a small known amount of grain by each of several active burrowi. Check the bait the next day or two to determine if the grain was consumed. Baiting should be delayed until untreated grain is being readily accepted. If the untreated grain is not accepted this indicates that it would be a poor time to use the toxic bait.

Figure 2 illustrates some general guidelines for Columbian ground squirrel bait acceptance. Note that bait acceptance in early spring is generally poor. The squirrel's preference for succulent forage and lack of natural seed production at this time of year usually results in poor bait acceptance. This is unfortunate because early control would be desirable to prevent spring crop damage and reduce the number of squirrels born that year. Early spring baiting is sometimes successfui but should not be conducted without assuring the bait will be accepted.

The question of when to bait Columbian ground squirrels is very complex and there are presently no "hard and fast" answers. Each person must determine the precise timing for his own area by observation of ground squirrel activity and testing of bait acceptance by the method described above.

\section{USE QUALITY BAIT}

When toxic baits are applied they must compete with the other food items on which the squirrels are foraging. It is important for the bait to be the best quality possible. It is recommended to use fresh bait. The potency of the bait does not degrade but the palatability may if during storage, the bait has dried out or become contaminated. If bait must be carried over to the following year, store ir a cool to moderate temperature to reduce dehydration. Store separately in a weatherized, Inouse-proof area to prevent contamination from other chemicals, moisture or mice.

\section{BAIT SHOULD BE USED ONLY ONCE PER YEAR}

If control is poor initially, re-baiting will probably give poor control also. The squirrels surviving the original baiting operation may have eaten some of the bait and became ill. These squirrels will be reluctant to consume bait the second time. For this reason, it is important to time the application when bait acceptance tests show good bait acceptance.

\section{PLACE THE BAIT PROPERLY}

Proper placement of bait is critical for successful control. The amount of bait specifiea on the label should be scattered, not piled, adjacent to each active burrow. Scattering grain over a 2-3 square foot area will increase bait acceptance and decrease the 
hazard to livestock and nontarget wildlife. Piling the bait increases the chance livestock and nontarget aninais will find and eat the bait. In most instances placement of bait down the burrow decreases the degree of control achieved. As ground squirrels move in ana cut of their burrows and move soil during burrow maintenance activities the bait will often be buried. Squirrels are more accustoned to foraging above grcund for their food and less likely to accept bajt found in the burrow. All active burrows must be baited. Incomplete coverage of a squirrel colony will result in poox coritrol.

\section{FREBAITING WIJI, INCREASE HAIT ACCEPTANCE}

Prebaitirg involves haiting with untreated grain several days before using toxic grajr. This accustoms the squirrels to eating yrain. Studies have shown prebaiting improves bait acceptance, and therefore, control. The major disadvantages are increased cost and labor. Prebaiting by mechanical spreaders will save time and may be less expensive than prebaiting by hand.

\section{BUFFER ZONES}

Columian ground souirrels are capable of moving considerable distances. Some individuals may disperse up to a mile from their birth area but most probably move less than 250 yards. This fact must be considered when conducting a control program. An uncontroiled population of squirrels bordering a treated area may invade the treated area almost immediately. Within a short time it may appear that no treatment occurred on the treated area. The result may be that the squirrel population on the treated area may return to pretreatment levels by the following year.

Immediate reinvasion can be reduced by treating a buffer zone around the area to be protected. If good control is obtained on both the crop area and the buffer zone, retreatment should not be necessary for at least one year. In some cases protection of the crop area may last two or three years before retreatment is necessary. Treating a buffer zone is initially more costly but it is less expensive over the long term because of increased crop protection. A buffer zone 250 yards wide is recommended.

\section{SAFETY}

The pesticides discussed here are not specific to killing ground squirrels. If not properly used they can injure or kill wildije, domestic pets and livestock and people. Read pesticide labels completely and follow the directions and precautions. Buy no more burrow fumigants or toxic baits than can be used in one season. They can lose their effectiveness over time. Keep all pesticides in their original, labeled containers. Do not reuse empty contairers. Destroy containers when empty. Consult the label recommenciations for proper disposal: When rot in use kefp in locked, rodent proof storage. 
Hazards to nontarget animals from toxic baits are present in two ways: primary poisoning - direct consumption of the bait material; and secondary poisoning - consumption of poisoned squirrel carcasses by predators or scavengers.

Nontarget animals most at risk from primary poisoning are domestic livestock and poultry and certain seed-eating wildlife species including waterfowl, grouse and some songbirds. Hazards from primary poisoning can be reduced by following pesticide label directions and precautions and common serse safety practices such as:

1) keep baits jn original labeled cortainers and store in locked weather tight storage when not in use.

2) during application keep excess bait in locked or latched storage to prevent access by livestock or chllaren.

3) use calibrated dippers or spoons for applying bait. Apply only the label recommended amount. Scatter the bait over a 2-3 square foot area near each active burrow. Do not pile the bait because this increases hazard to livestock and wildife and it is not a natural food placement for squirrels.

4) Remove livestock from treatment areas when possible. In addition to reducing risk to livestock, ground souirrel control will improve if livestock are not trampling on bait placements.

5) In areas known to be frequented by waterfowl or other seedeating birds consider additional precautions such as patroling the area or using scarce devices after bait application. Consider use of alternative methods such as burrow fumigants or bait stations in high risk areas.

6) Pick up and bury any spilled bait.

Secondary hazard from bait rodenticldes results from the presence of quantities of residual poison in ground squirrel carcasses. With strychnine, most of the residual poison is concentrated in the digestive tract. Animals that consume the entire carcass such as dogs, coyotes, badgers and owls are most at risk. Animals that remove and discara the digestive tract such as most species of hawks are at considerably less risk from secondary poisoning. When practical, burial of ground squirrel carcasses helps reduce the hazards to potential nontarget animals. Always notify neighbors of your bait applications. Suggest confinement of dogs, cats or other animals for a period of time after bait application. In warm weather, carcasses decompose rapidly and present little hazard after 5 to 10 dàys.

As with most programs, rodent control will be most effective where a coordinated effort is established by all landowners. The Montana Department of Agriculture personrel, upon request, will work with 
county commissioners, extersion agents, and landowners to establish a program suited to local and county needs. Field demonstrations are provided to inform landowners how, when, and where to control Columbian grourd squirrels and other field rodent pests.

Interested individuals should contact their county commissioners, courty exterision agents, or the Montana Department of Agriculture, Capitol Station, Helena, MT 59620, (444-2944), or your Area

Vertebrate Pest specialists:

$$
\begin{aligned}
& \text { Monty Sullins - Eastern Montana (Lewistown) - 538-2182 } \\
& \text { vaniel Sullivan - Western Montana (Helena) - 444-2944 }
\end{aligned}
$$

Additional ground squirrel control bulletins are available from the Nontana Department of Agriculture:

"Managing Ground Squirrels with Bait Stations"

"Controlling Burrowing Rodents with Burrow Fumigants" 


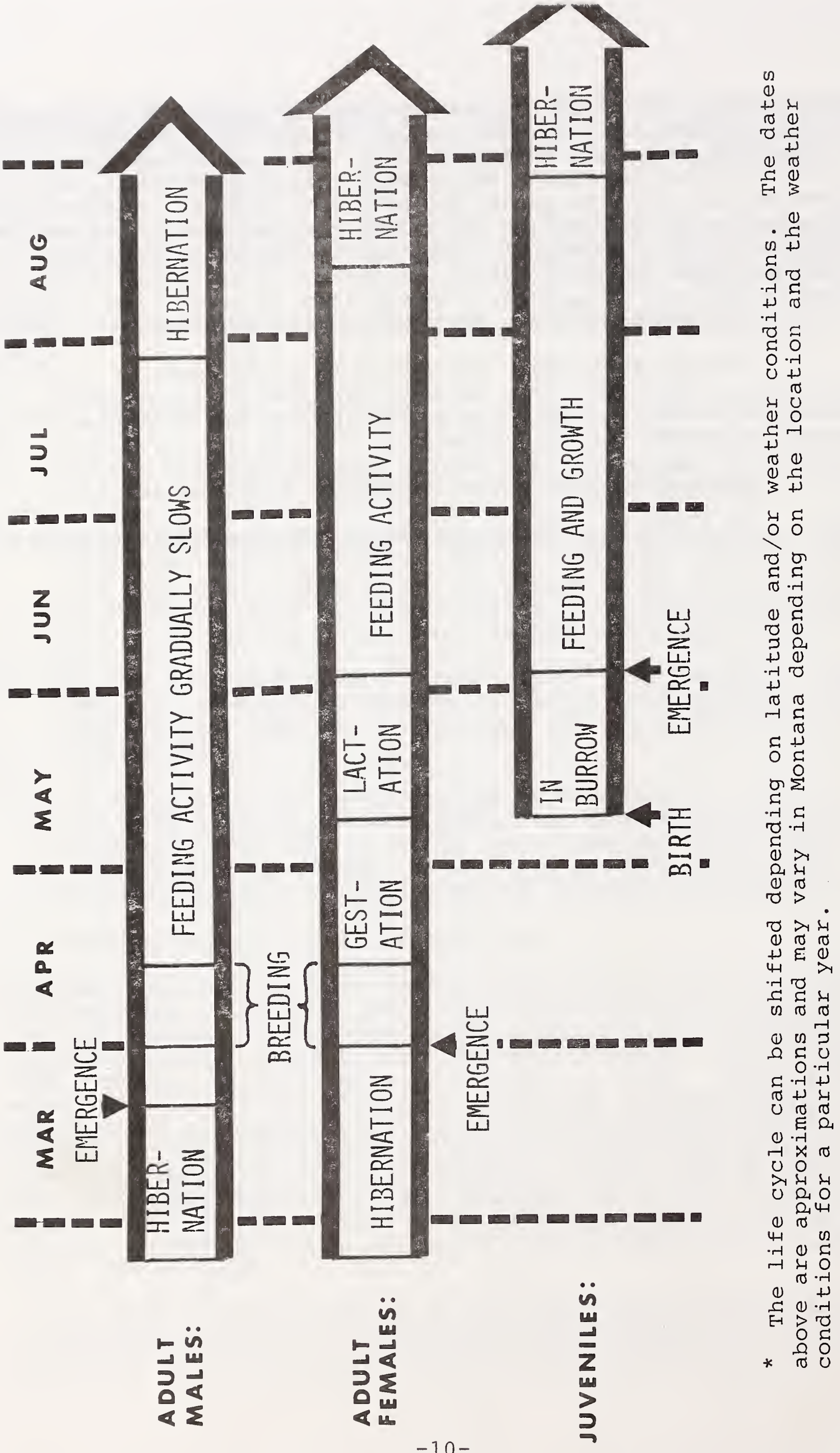




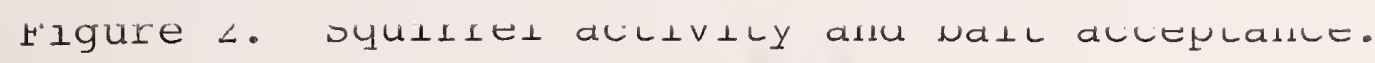

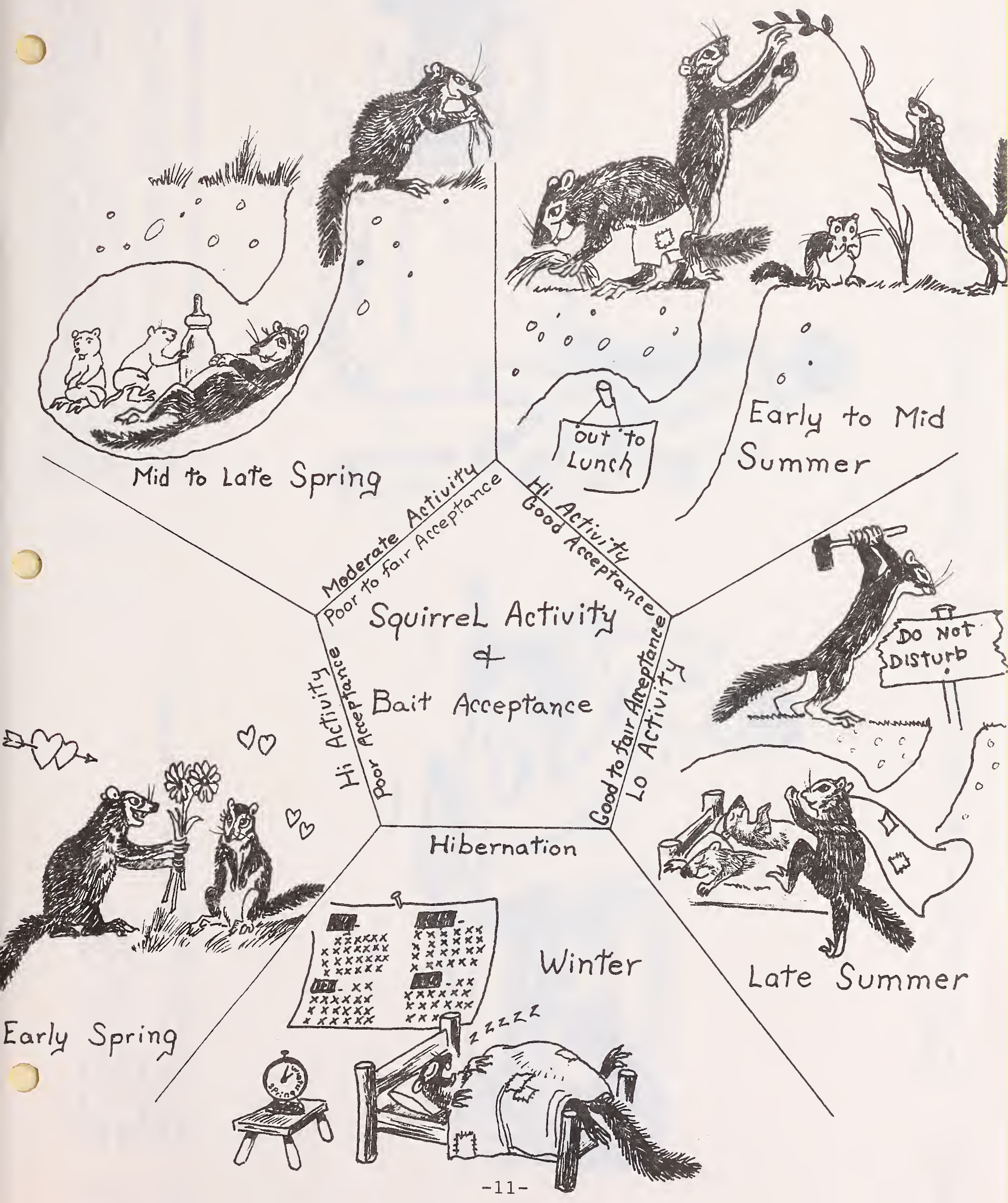



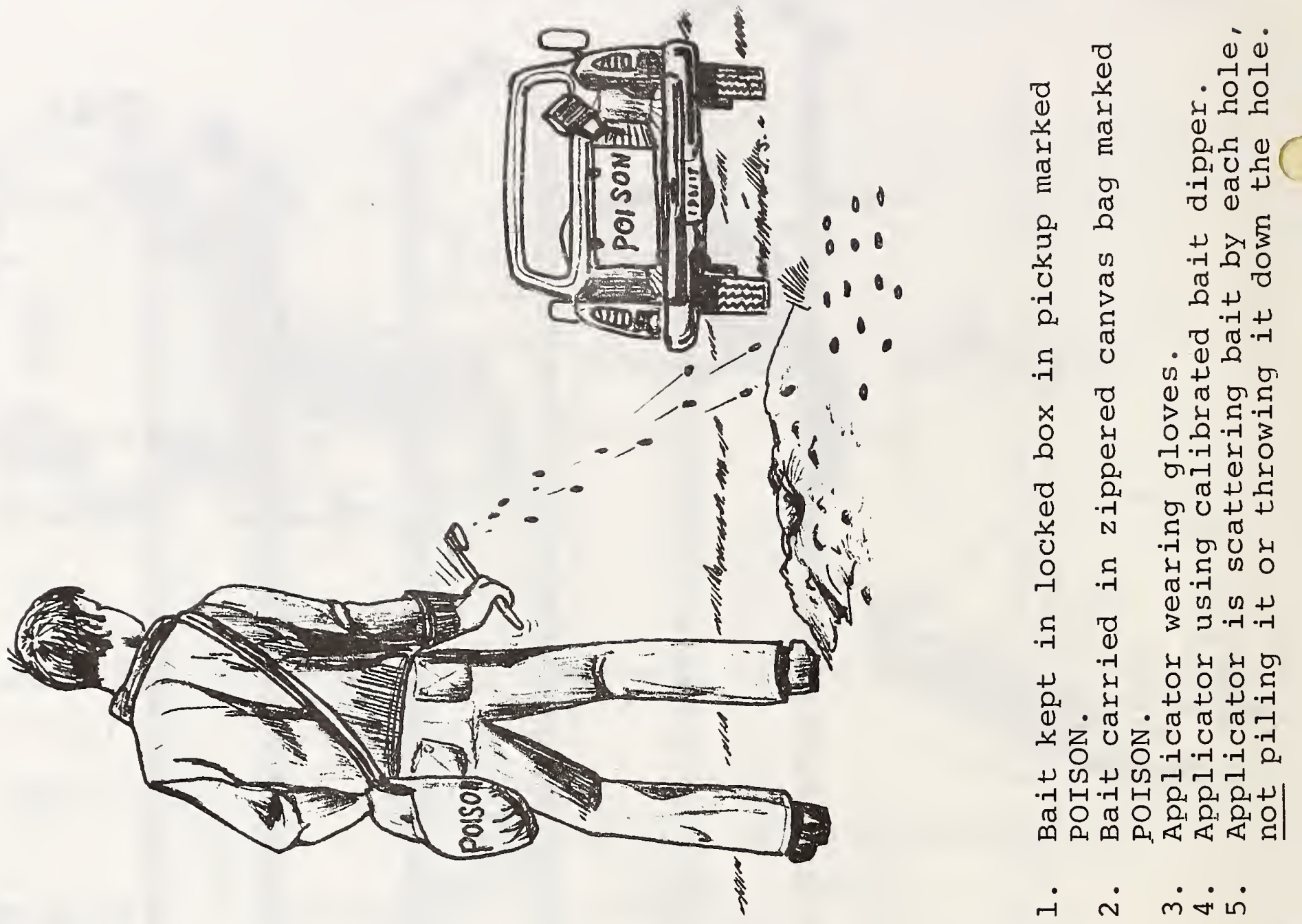

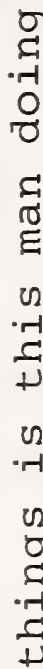

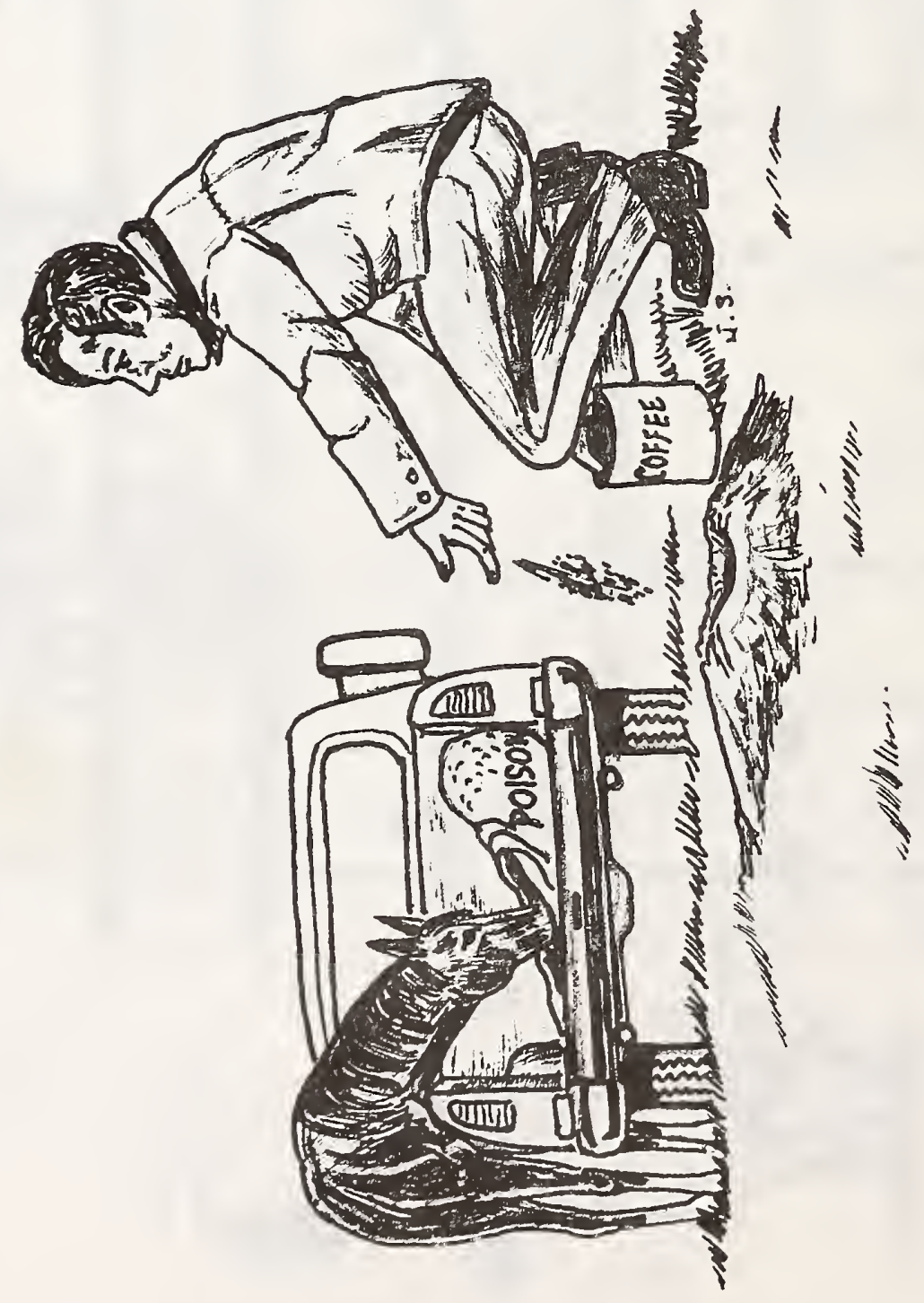

4
0
0
0
0
.4
0
.
.1

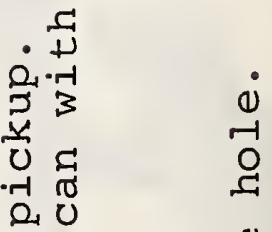

द्व

की कि

त 0.73

Q द $>0$

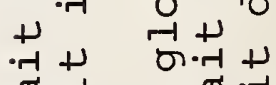

त

๑

द $\dot{1}$ पे

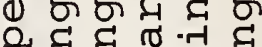

O.

तान 3 ऽ 3

+4 मे

4 मे 0

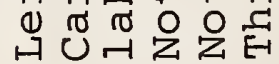



